\title{
LA ÉTICA COMO ARTE SUSTITUTIVA DEL FAVOR DIVINO: ESQUINES Y ARISTÓTELES
}

\author{
ETHICS AS SUBSTITUTE TECHNIQUE OF DIVINE \\ DISPENSATION: AESCHINES AND ARISTOTLE
}

\author{
Diego Pintado ${ }^{1}$ \\ Investigador independiente
}

Recibido: 24/ 2/ 16

Aceptado: 16/ 5/ 16

\begin{abstract}
Resumen: Este conciso trabajo monográfico consiste en explicar el concepto originario de virtud, tanto en Esquines como en Aristóteles, y las conflictivas implicancias en una sociedad religiosa como lo era la griega, contrariamente a la idea tradicional un tanto deformada que concibe a la Grecia antigua como un paraíso de laicismo, racionalismo y libertad de pensamiento. La virtud fue en sus orígenes vista como un artificio, como una creación humana, para alcanzar la felicidad, la eudaimonía, y esto de alguna manera entraba en oposición con los designios divinos, que ya habían previsto a quién le correspondía la dicha y la fortuna y a quien no. Se indagará cuál fue, asimismo, la reacción moralizante de Platón. También se transita la concepción aristotélica del arte y su relación con la ética, y se explora el giro que sufre la ética en dos obras que llevan el mismo nombre, Alcibíades: de qué forma la finalidad utilitarista de la ética presentada en la versión de Esquines hace un viraje hacia una finalidad deontológica y moralizada en la versión de Platón. Por último se analizan unos extraños pero elocuentes fragmentos de Esquines que hacen notorio este dilema perenne para la ética: ¿el ser humano debe consagrar su vida a la felicidad o al deber? ¿debe el hombre acatar los designios divinos, aunque no hayan sido con él auspiciosos y lo hayan privado de la felicidad, o debe enfrentar las adversidades de su condición y fabricarse un artificio mediante el cual pueda obtener esa felicidad que le fue negada?
\end{abstract}

Palabras clave: ética, filosofía antigua, Aristóteles, Esquines, utilitarismo, eudaimonía.

1. (nulliusinverba@outlook.com) Buenos Aires. Investigador independiente - Estudiante de Filosofía (UBA - USAL). Estudiante de sánscrito - Estudios Orientales (USAL, interrumpidos). Traductor (Nietzsche, F., Ditirambos dionisíacos, Vajra Ediciones, 2012). Autor de otros artículos próximos a publicarse en este año 2016: "El concepto de metron en Heráclito y Protágoras", "El secreto de la reminiscencia en el orfismo y en Platón: propuestas hermenéuticas para una nueva aletheiología", "El principio de ontingencia en la ética: una presentación introductoria al problema" y "La gravedad en Bruno, Kepler y Newton: la distribución de la materia y sus implicaciones cosmológicas". 


\begin{abstract}
This paper treats on the origins of the concept of virtue, in Aeschines and in Aristotle, and the unsettled implications in the ancient greeksociety. In the beginnings, virtue was contemplated as a man-made device, as a human creation, in order to achieve happiness, eudaimonia, and this artefact (we call virtue) was, in some way, long ago, seen as opposed to the divine designs. If Fortune (God, Fate, Providence) already predeterminated who is going to be happy and safe and who is going to be unfortunateand helpless, then what does mean this presumptuous invention we call virtue, created for the purpose of obtaining those same gifts that only the Gods can provide? On the other hand, this short monograph is about the problem of the origin of technique and art, according to aristotelian thought. It treats on virtue, happiness and divine dispensation in Aeschines and in Aristotle.
\end{abstract}

Key words: ethics, ancient philosophy, Aristotle, Aeschines, utilitarism, eudaimonia.

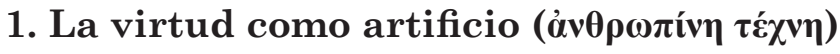

En la Ética Nicomaquea, Aristóteles nos dice que lo esencial al hombre es la felicidad: su tarea esencial, su función, es alcanzarla; su sentido por naturaleza es ser feliz. La eudaimonía es la finalidad del ser humano y su razón de ser. Aristóteles explica las condiciones, variables y requisitos necesarios para obtener la felicidad, y entre ellos deben incluirse aspectos exteriores y la garantía de su conservación hasta el final de nuestras vidas: se necesita de bienes externos, amigos, riqueza o poder político, o noble ascendencia, de buenos hijos y hasta de alguna belleza física ya que no habría felicidad si se está condenado a la soledad y privado de tener hijos, como tampoco la habría si nuestros hijos son causa de disgusto e infelicidad, de manera que sin esta prosperidad elemental, con base en bienes exteriores, la felicidad no es posible ${ }^{2}$. Sin embargo, Aristóteles no nos dice que la felicidad sea resultado de una vida en conformidad con la filosofía, ni siquiera en conformidad con la prudencia: nos dice que también es posible ser felices sin la filosofía y sin la prudencia - es decir, ¡sin ser virtuosos! ... ¿y cómo sería eso posible? Sería posible si tenemos el favor divino.

Este punto puede aparecer controvertido, porque accedemos a Aristóteles a través de la tradición, y la tradición fue la que suscitó la controversia: el punto es si hay felicidad sin virtud. La postura de Aristó-

2. Esta enumeración de bienes y requisitos externos excluyentes para la felicidad se describen en el último párrafo del capítulo VIII del libro I: 1099a28-b7.

Thémata. Revista de Filosofía $\mathrm{N}^{\circ} 55$ (2017) pp.: 27-40. 
teles es bastante explícita: la felicidad depende de muchas cosas, entre las cuales se cuentan cosas externas, que dependen de la suerte o fortuna de cada uno; la felicidad es frágil y cambiante como la suerte, de modo que tanto para el feliz como para el infeliz sería una tontería despreciar la virtud: para el primero, porque la virtud le permitiría guarecer a la felicidad y evitar errores que lo lleven a perderla, y para el infeliz, la virtud le permitiría sobrellevar su infelicidad de una mejor forma. Pero Aristóteles le interesaba la verdad, y no estaba cegado por presupuestos religiosos o moralistas que condicionasen su investigación sobre la ética; Aristóteles sabe lo mismo que sabe cualquiera de nosotros: que hay, y hubo, innumerable cantidad de gente que llevaron vidas felices, en el más íntegro y cabal sentido del concepto aristotélico de eudaimonía, sin ser virtuosos ni inteligentes; está lleno de personas que no ejercen prudencia ni previsión ni filosofía alguna respecto a los pasos que deben tomar en su vida, y no obstante así, con ayuda de la fortuna, nada les hace falta, de todo están provistos, y, ante una decisión que deben tomar, aciertan, o no, pero en ningún momento pierden su estado de felicidad.

Lo fundamental es la Suerte, la Fortuna, la Divinidad: es la bendición divina, su gracia, su auspicio, y sólo ella, la que puede donarnos una vida feliz. Ninguno de los componentes enumerados por Aristóteles en Ética Nicomaquea implica como condición necesaria a la sabiduría ni a la prudencia. Aristóteles es claro en eso, y esto es escándalo de cualquier virtuosismo deontológico que se quiera apropiar de Aristóteles, y de cualquier moralista o teólogo que creyó desde siempre tener en Aristóteles a un infalible y sólido aliado. Pero todo esto es inequívocamente corroborable, sin ambigüedades, en la Ética Nicomaquea: "si hay algo que los dioses tienen

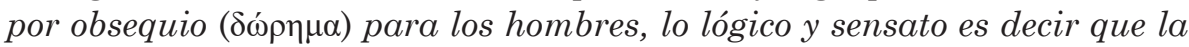
felicidad es un don divino, más todavía considerando que es lo mejor y lo más grande que existe entre los humanos"3, y de esta forma se resuelve el dilema acerca de si la eudaimonía o felicidad "es algo que puede ser aprendido, o adquirido mediante el hábito o mediante alguna práctica o ejercita-

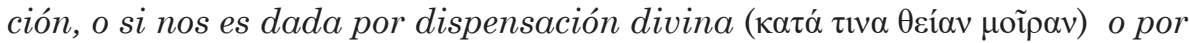

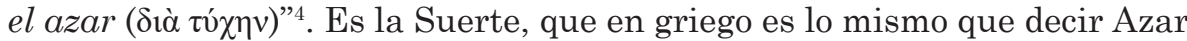
o Dios o los Dioses, la que da la felicidad. La virtud no es necesaria para la felicidad, ya que nada puede hacer por sí misma para proveerla, dado que sólo la dispensación divina la concede, y de ella dependemos en última instancia para adquirirla, pero si bien no es necesaria, es recomendable y sería un despropósito dejar todo librado al azar; es por eso aconsejable practicar la virtud: tanto para el feliz y dichoso y afortunado, para que

3. Ibid, 1099b12-15.

4. Ibid, 1099b9-12.

Thémata. Revista de Filosofía N55 (2017) pp.: 27-40. 
pueda consolidar su felicidad, protegerla y asegurarla, así como para el infeliz, para que pueda enfrentar las adversidades de la vida con magnanimidad y nobleza. ¿Y qué es entonces la virtud, para la cual necesitamos de la prudencia, propuesta por Aristóteles? Es un medio sustituto para alcanzar aquello que no nos fue dado por dispensación divina: la felicidad. Pero aún así, este medio sustituto no puede darnos ninguna felicidad si no contamos con la ayuda de bienes externos y condiciones favorables, es decir, si no contamos con la ayuda del azar o de la gracia divina. ¿Y entonces para qué sirve la virtud? Insistimos: sirve al afortunado para reforzar y custodiar su felicidad, mientras que al desafortunado le sirve para sobrellevar con grandeza espiritual su condición de desdicha.

Ahora bien, ¿podemos ver este mismo problema filosófico y ético en los fragmentos de Esquines? En mi opinión, este problema sí está en los fragmentos, a pesar de que el contexto en el que sobreviven estos trozos de texto suelen ser confusos, ambiguos y a veces hasta nos imponen mantener alguna reserva sobre la intencionalidad de quienes los reproducen y el contexto en el que los ubican; en mi opinión, decía, este problema está tratado por Esquines con delicadeza y cautela, porque sabe que la problemática que está involucrando es muy seria: por una parte, la elaboración de una técnica para sustituir lo que viene del Cielo, el don y el favor divino, y por el otro, la posibilidad implícita de ser felices... isin ser virtuosos! El problema que estamos tratando, concerniente a Aristóteles y Esquines, justamente revela y habilita que es posible:

— ser virtuosos y no ser felices,

- ser felices sin ser virtuosos,

- ser virtuosos sin la ayuda divina,

- y tener la ayuda divina sin ser virtuosos.

Esto es grave, es espinoso y delicado: lo es para la filosofía, para la ética, para la jurisprudencia y la para religión. ¿Qué nos dice Esquines en su diálogo en los fragmentos recogidos por Arístides ${ }^{5}$ ?

Creer que podemos, en tanto seres humanos, elaborar útiles — ¿útiles para qué? ¿para resolver los problemas últimos y existenciales? ¿para darnos la felicidad o la salvación? ¿para dotarnos de aquello que el Cielo olvidó selectiva y discriminativamente proveernos?-, creer, decíamos, que podemos elaborar útiles para suplir eso con una técnica humana implicaría que se nos acuse "de una ingenuidad total, mientras que hasta ahora creía que esto me había sido dado por dispensación divina", como

5. Dittmar, H. (1912), Aischines von Sphettos, Studien zur Literaturgeschichte der Sokratiker, frag. 12, Weidmann, Berlin.

Thémata. Revista de Filosofía $\mathrm{N}^{\circ} 55$ (2017) pp.: 27-40. 
dice Esquines en su Alcibíades, según fragmentos recogidos por Arístides. Lo que podamos elaborar, por tanto, no es digno de admiración. O sea: claramente jamás podremos sustituir la dispensación, el don divino (la $\theta$ cia poipa); jamás podremos igualar el arte y la efectividad y la perfección de la providencia, o sea, de la suerte/gracia dispensada por el Cielo. La naturaleza, o mejor dicho Dios, siempre harán cosas mejor de lo que las pueda hacer el hombre. Eso está bien claro - advierte Esquines y a la vez parece prevenirse de cualquier acusación de impiedad o irreverencia religiosa-y eso debemos tenerlo siempre en claro y no perderlo nunca de vista: aún cuando no se trate de una completa estupidez, lo que podamos elaborar como sustitución no será nunca "algo digno de admirarse". Pero...

...y acá viene la declaración, más formal, de lo que quiere asentar su propuesta ética y su filosofía, cuando dice: "porque muchos de los enfermos se curan, unos por técnica humana, y otros por dispensación divina": es decir, es evidente y nadie duda ique la sustitución funciona! Funciona, porque "muchos enfermos se curan", inclusive cuando no sea comparable al obrar divino ni digna de admiración. O sea: es posible, aún cuando el designio y el auspicio divino no esté con nosotros, o se haya olvidado de

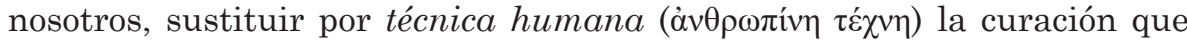
necesitamos. Esquines no solamente está proponiendo una ética, o una

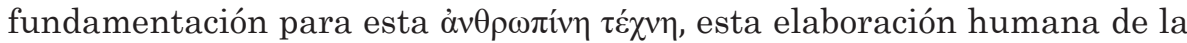
ciencia y del arte. Sino que está proponiendo sustituir la falta o ausencia o desprovisión divina.

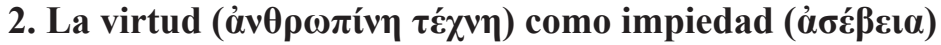

Preguntarnos si la virtud, originariamente, fue contemplada como una impiedad, o como próxima o lindante con lo impío, es una cuestión que para nosotros se presenta incongruente y poco comprensible, porque nuestra cultura y nuestra tradición ha deontologizado a la virtud, o sea, la ha subordinado a la moral y al deber, cívico o religioso. Pero si pensamos que, en sus orígenes, la virtud no era deontológica, y que su razón de ser no era otra que una razón de ser... jutilitarista!, es decir, en función de la utilidad en orden a mejorar nuestras vidas y proveernos de lo que la naturaleza, esto es el azar, esto es la dispensación divina, no nos ha provisto, entonces no nos costará tanto esfuerzo entender que la virtud pudiera ser sospechosa de impiedad: la virtud vista como algo más propio de Dédalo o de Prometeo que del ejemplarísimo Sócrates que Platón nos describe.

Recordemos, de pasada, que Gandhi se opuso a la construcción de hospitales porque los enfermos debían pagar karma con su enfermedad; recordemos asimismo que el monje cristiano Pelagio, combatido por Agus-

Thémata. Revista de Filosofía N55 (2017) pp.: 27-40. 
tín como el más execrable hereje de su tiempo, lo que proclamó fue que el hombre podía salvarse y alcanzar el regnum dei por sus propios medios, por sus propias obras y tenacidad espiritual y perseverancia, mientras que el santo africano oponía que sólo puede haber salvación por intervención de la gratia. Quiero decir: no estamos frente a temas menores, y las implicancias en juego son de un alcance imprevisible tanto para el que las proclama como para la sociedad en la que se proclaman y sus respectivos estamentos institucionales.

¿Es posible que Esquines, o el personaje que retrata en esos fragmentos, se esté disculpando por la introducción de una nueva técnica, o sea, mejor dicho, se esté disculpando por inventar algo útil que pudiera sustituir o emular el obrar de la naturaleza o de lo divino? Evidentemente que sí, porque advierte que es pretensión completamente estúpida, y deja de serlo sólo en la medida que admita y no olvide que tal cosa nunca alcanzará a ser digna de admiración, esto es: nunca será igual ni estará al nivel del obrar divino. Ahora bien: ¿pudo en esa época haber habido un recelo o animadversión o desconfianza respecto a los desarrollos científico-técnicos, desde la medicina y la física hasta la retórica y las ciencias políticas? Indudablemente. Además, como ejercicio, podemos plantearnos: ¿acaso no nos resulta contranatural la idea de que mañana alguien presentara y a la humanidad un hipotético invento de una juventud eterna? ¿por qué muchos de nosotros la rechazamos, o tal vez a lo sumo nos parecería aceptable tan sólo limitarnos a comprar apenas unas décadas más de "juventud eterna", tratándose de algo que en principio no parece contraer absolutamente nada malo ni perjudicial para nadie, sino un milagro de la inventiva humana? Estamos seguros de algo: mucha gente se alegraría y trataría de adquirir esa eternidad de juventud, pero mucha gente no, muchos rechazarían esa inmortalidad como algo sospechoso, innatural, luciferino. Quizás un poco eso era lo que sucedió en Grecia con algunos desarrollos técnicos, ya sea para curar o cualquier otra cosa. Hay muchas sociedades, más próximas a nosotros y hasta contemporáneas, que están más bien entregadas a los designios divinos ocultos detrás de una aparente fatalidad. En la India tenemos un ejemplo, pero también más cerca en el cristianismo: tradicionalmente el sufrimiento no era algo que debía ser rehuido o rechazado, sino abrazado, porque era una forma de abrazar la cruz y llevarla en el calvario de la vida. Cualquier propuesta francis-baconiana de un paraíso terrenal es luciferismo y es rechazar a Cristo rechazando a su cruz. ¿Por qué no pensar que el desarrollo de una tecnología para obtener el bienestar del cuerpo y del alma, o sea, la salud y la felicidad, no era vista por los antiguos griegos sino como una tentación prometeica, que además tendría la consecuencia práctica inmediata y palpable que sería el debilitamiento del poder y la necesidad de la casta sacerdotal dispensadora de

Thémata. Revista de Filosofía $\mathrm{N}^{\circ} 55$ (2017) pp.: 27-40. 
milagros, curaciones para el cuerpo, iniciaciones místicas-sacramentales para la salvación futura y consuelos y bálsamos efectivos para el alma en la vida presente?

Es muy interesante observar la cautela que introduce Aristóteles cuando tiene que encarar este punto crucial y tan delicado: "Por lo demás, no quiero profundizar esta cuestión, que pertenece quizá más especialmente a otro orden de estudios. Pero digo, que si la felicidad no nos la envían exclusivamente los dioses, sino que la obtenemos por la práctica de la virtud, mediante un largo aprendizaje o una lucha constante, no por eso deja de ser una de las cosas más divinas de nuestro mundo, puesto que el precio y término de la virtud es evidentemente una cosa excelente y divina y una verdadera felicidad"6. ¿Quiere decir que, inclusive cuando no recibamos la felicidad de manera directa y divinamente gratuita - ex gratia - y debamos obtenerla mediante "largo aprendizaje o lucha constante", aún en ese caso, también le debemos esta virtuosa tenacidad en la lucha y el aprendizaje a la gracia divina? ¿O significa que mediante trabajo y sacrificio - mediante la técnica y el esfuerzo humano, o sea: ex operibus - podemos sustituir el favor divino, la gratia de la Suerte, la bendición de la Fortuna? Pareciera darse la problemática y la delicadeza de la cuestión en términos inversos a los nuestros: mientras que muchos intérpretes y traductores intentan hacer prevalecer una versión virtuosista de la Ética Nicomaquea, tenemos

6. En este caso no es nuestra la traducción, sino que preferimos citar la de Patricio Azcárate, pasaje 1099b 10-20. Además es mucho más clara y menos tendenciosa en estas líneas que la de Sinnott, quien omite el condicional en 1099b15 (...eỉ $\mu$ 门́... etc.) y traduce deslucida y brumosamente: “(...) es manifiesto que, por más que no es mandada por los dioses sino que nos es dada por virtud y cierto aprendizaje o ejercicio (...) [la dicha] se encuentra entre las cosas más divinas (...)", lo que cambia totalmente el significado de la versión por la que en este caso hemos optado: “(...) si la felicidad no nos la envían exclusivamente los dioses, sino que la obtenemos por la práctica de la virtud (...) no por eso deja de ser una de las cosas más divinas de nuestro mundo (...)". La tendenciosidad latente en la traducción confusa que Sinnott hace de este pasaje, se debe a una motivación moralista y deontologizante que el autor hace evidente en una aseveración errónea que realiza a pie de página - y no es la única-, empeñado en hacer de la felicidad un fruto exclusivo de la virtud y no de la Suerte o del favor del Cielo, en la nota 164: "Se sobreentiende sin duda que si la dicha se debiera a un favor divino, sería un hecho raro", correspondiente al pasaje 1099b18-20, donde según su propia traducción Aristóteles dice: "Pero [la dicha] puede ser también común a muchos [hombres], pues es posible que se dé, mediante cierto aprendizaje y dedicación, en todos los que no están incapacitados para la virtud". De manera que, contrariamente a lo que sostiene Sinnott, no se sobreentiende nada de eso: se sobreentiende justamente lo contrario de lo que él da por sobreentendido; o sea, lo que en rigor de verdad se sobreentiende es que toda dicha o felicidad descansa siempre, como conditio sine qua non, en bienes, condiciones y circunstancias que a su vez descansan siempre y como conditio sine qua non en la dispensación divina: lejos de ser "un hecho raro", es en realidad un hecho imposible que pudiera haber felicidad sin el favor del azar, la suerte, los dioses, la gracia o la fortuna. Por lo tanto, la aclaración de Sinnott no aclara sino que confunde, y este error obedece a una manifiesta intencionalidad de procurar una interpretación moralista y deontológica de la Ética aristotélica.

Thémata. Revista de Filosofía N55 (2017) pp.: 27-40. 
en cambio a Aristóteles que, para resguardarse de cualquier sospecha de impiedad, intenta tomar distancia de un virtuosismo fuerte, o extremo, y dejar a la obtención de la felicidad supeditada siempre y en cualquier caso - y bajo cualquiera sea el medio por el que haya sido obtenida - en la divinidad como la causa prima de la felicidad natural o donada tanto como de una hipotética felicidad esforzada o ganada. ¿Por qué se da está inversión en los términos de la cautela? Porque para nosotros la virtud es deontológica, mientras que para Aristóteles, mal que le pese a los intérpretes moralizantes, es utilitarista. De modo tal que Aristóteles, para proteger a su virtud utilitarista de acusaciones de impiedad, cuidadosamente deja bien en claro que esta virtud, en última instancia, por más utilitarista que sea, no deja por ello de ser también un don divino. Pero, mutatis mutandis, los intérpretes moralizantes de la tradición ponderan a la virtud por encima de todo y, al revés completamente de lo que quiere enfatizar Aristóteles, soslayan el peso de la fortuna y de la dispensación divina en la ardua tarea que insume lograr la felicidad.

Como quiera que sea, vemos a Aristóteles protegerse como aquel que, provisto con algún don o habilidad para sanar enfermos, se previene de cualquier acusación de brujería aclarando que ese don lo recibió de Dios y que es Dios, y no él, el que a través de él está curando, y por otra parte tenemos a Esquines, salvaguardando a la técnica humana, sustituta del favor divino, de cualquier acusación de impiedad prometeica. En Aristóteles lo importante es que de lo todo lo bueno y maravilloso el responsable último siga siendo la Divinidad, mientras que en Esquines lo importante es conseguir la aceptación de "lo útil" como algo legítimo y que no representa ninguna rivalidad ni desafío respecto del sabio designio divino. La conclusión que se desprende de todo esto es un poco incómoda, y nos ayuda a entender los recaudos tomados por estos filósofos: ambos presentan, fuera de toda discusión, una ética utilitarista - aunque podemos conceder que el utilitarismo griego no es el mismo que el de la ética utilitarista moderna y contemporánea: el sentido de utilidad está lejos de ser el del utilitarismo anglosajón, y mucho más próximo, aunque desde luego sin serlo de ninguna manera, al sentido propio de una reforma o transformación religiosa.

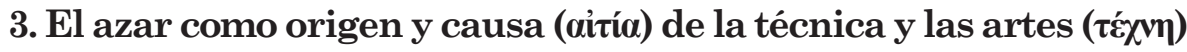

Para Aristóteles la técnica no era una bendición del Cielo a los seres humanos ni un lujo espiritual que podía desarrollar una civilización o comunidad satisfecha y próspera con mucho tiempo de ocio. Para Aristóteles la técnica se origina en el azar y ahí tiene su causa. ¿Qué es para él el azar, en este sentido? Es el caos, la contingencia, la imprevisión de 
la existencia humana. Es la desprovisión: es el estado de desamparo. La arquitectura, por ejemplo, surge ante este desamparo, es originada por él: el hombre no puede dormir a la intemperie, ni en el suelo rodeado de bichos y serpientes, ni bajo un sol calcinante ni expuesto a un frío helado, ni desprotegido. Debe edificar y ser previsor, crear resguardos, es decir: artificialidad, con la naturalidad no alcanza. La naturaleza o Dios no nos proveyó de todo (o sí, tal vez nos proveyó de la capacidad para sustituir lo que no nos proveyó a priori, quién sabe). El concepto aristotélico de arte, arte como $\tau \dot{\varepsilon} \chi v \eta$, es muy diferente al que tenemos nosotros; el nuestro es más bien un poco optimista o evolucionista, y el de Aristóteles está más bien anclado en la necesidad de sobreponerse al desamparo del azar y la contingencia, y la desprovisión.

Entonces la ética no-moralista y no-deontológica, es decir, la ética tal como la entendieron los sofistas, los socráticos y Aristóteles, la ética orientada a la felicidad o al placer o al bienestar, debió ser vista como una tecnología innatural y poco menos que impía para sustituir el obrar divino, y proveernos (¿ilegítimamente? ¿contranaturalmente?) de lo que el Cielo no nos aprovisionó. Incluso hoy día, una lectura de la Ética Nicomaquea, orientada en esa dirección, crearía incomodidad y rechazo, y no cabe duda: es por lo menos un baldazo de agua helada que uno de los más grandes filósofos de todos los tiempos nos diga que

- los no virtuosos, o nada virtuosos, pueden ser felices,

-y que puede alcanzarse la más plena felicidad sin virtud,

- y que la persona que cultiva y desarrolla capacidades intelectuales no es debido a una superioridad sino a una necesidad que otras personas, más afortunadas y benditas por la disposición divina o por la naturaleza, no tienen,

- y, acá viene lo peor: que la virtud, en su esencia, no proclama vivir de acuerdo con el Deber o la moral o el compromiso cívico o social o el servicio religioso y piadoso, sino que es un complejo y sofisticado arte dispuesto en orden a obtener la propia felicidad, vivir una vida plena e íntegramente feliz.

\section{Platón y su reacción moralizante: el "giro deontológico"}

A diferencia de la ética que encontramos en Esquines y otros sofistas y socráticos, y que luego reencontramos en Aristóteles, en Platón la ética se subordina a la moralidad. En el Alcibíades de Platón notamos un sistemático empeño por subordinar lo útil a lo justo y lo bueno. Esto 
quiere decir: moralizar la ética, despojarla de su finalidad eudaimónica, o sanadora y curativa, presente en el diálogo de Esquines, y someterla al servicio de lo justo y lo bueno, y así tenemos la ecuación virtud = moral. Y esto implica, nada más y nada menos, una consecuencia en el orden antropológico; implica transformar la función, el épyov, del ser humano: su tarea natural no será ya obtener la eudaimonía, sino consagrarse a la justicia, las leyes, el bien metafísico. Podría decirse que Platón instaura un "giro deontológico" en la ética: el deber, con asiento en las altas esferas radiantes de belleza y bondad de la metafísica, se constituye en la razón de ser de la virtud. ¿Es el Alcibiades de Platón una respuesta, una reacción moralizante contra el Alcibíades de Esquines, con la ventaja de que las obras de éste último desaparecieron, o fueron intencionalmente desaparecidas? ¿se trata de una tergiversación espuria del diálogo en medio de una contienda descarnada entre sectores políticos y escuelas filosóficas partidarias o adversarias?

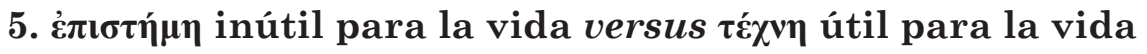

El problema capital en el Alcibíades tanto de Esquines como de Platón es lo útil. Vimos que lo útil en Platón es problemático y la resolución es subordinar la virtud —o mejor dicho, la utilidad- a la moralidad: lo justo y lo bueno. En Esquines, no pasa eso: lo útil es lo que cura, es lo que suple una carencia, es lo que sustituye al favor divino. La utilidad es un problema filosófico serio, y además inquietante, para los griegos de aquellas épocas. No es casual el resguardo y las poco menos que disculpas que anticipa Esquines al momento de abordar este punto. Sabe que se está metiendo en un territorio delicado por todo lo que involucra. Pero el problema de la utilidad no solamente confronta a moralistas con éticos, o sea, proclamadotes de la virtud como subordinada al bien contra proclamadores de la virtud como $\tau \dot{\varepsilon} \chi \nu \eta$ para adquirir la felicidad o el bienestar. También plantea una confrontación con quienes enseñan la ciencia y la sabiduría, y elevan el saber al más alto pedestal de aspiraciones al que debe dirigirse nuestra condición humana. Sabemos cuál es la razón de ser de la $\tau \dot{\chi} \chi v \eta$, ¿pero sabemos

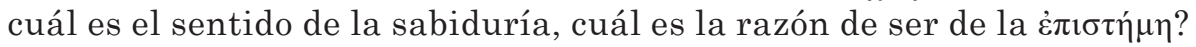
Respecto a la prudencia, hay un equívoco que persiste hasta hoy: se la asume como inseparable de la filosofía, lo cual es falso; para defender ese error, se argumenta que Aristóteles fundamenta a la prudencia en la racionalidad, pero eso de ninguna manera significa que la fundamenta en la filosofía: ya que la ciencia de un ingeniero, la técnica de un médico cirujano y la tarea desempeñada por un escribano, se

Thémata. Revista de Filosofía $\mathrm{N}^{\circ} 55$ (2017) pp.: 27-40. 
apoyan y se basan también en la racionalidad, y sin el razonamiento humano serían imposibles de ser, y sin embargo ninguna intervención tiene la filosofía en esas áreas. De tal forma que la prudencia aristotélica, además de no tener con la filosofía ninguna relación, y menos que menos una relación indisociable, parecería marchar por caminos bien distintos. Porque a la prudencia de Aristóteles no le interesa saber la verdad sino la utilidad, y la finalidad hacia la cual dicha utilidad es dispuesta.

Escribe Pierre Aubenque, en su obra La prudencia en Aristóteles:

La phrónesis no es todavía el saber socrático del no saber (sin duda, heredero suyo, aunque inconsciente), es un saber que desconfía de sus propios maleficios y se remite constantemente a la conciencia de sus límites necesarios. El Edipo de Sófocles se sacará los ojos por haber querido saber demasiado y no haber comprendido con suficiente rapidez la advertencia del adivino Tiresias: «^Ay! ¡Ay!

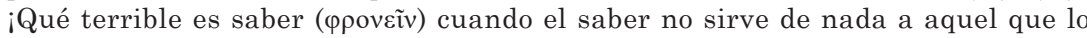
posee!». Aquí es el término ppoveĩv el que designa ese saber del que es un eufemismo decir que es inútil. Pero de este ppoveĩv que literalmente no aporta intereses ( $\mu \grave{\varepsilon} \tau \hat{\varepsilon} \lambda \eta \lambda \hat{v} \eta$ ), porque pretende penetrar los secretos del Destino y de la Fortuna, se puede pensar que Tiresias apela a una phrónesis más elevada, la que, limitándose, se exaltaría al rango de virtud y de la cual Edipo, ese "gran descubridor de enigmas», es cruelmente desprovisto. Este saber vano y eventualmente peligroso

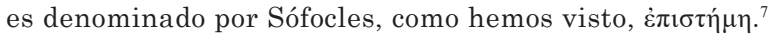

\section{6. "Estar habitado por el dios"}

Esquines dice algo más, que nos permitirá elucidar más impactantes consecuencias: "los que se curan por medio de una técnica humana quedan al cuidado de los médicos, y los que lo hacen por designio divino, el deseo los conduce a lo que les es más óptimo y favorable". La última parte de la frase es incluso un poco desconcertante. Pero en principio, ¿qué quiere decir Esquines con este añadido que acabamos de citar? Lo que quiere decirnos es que quienes mediante las artes y ciencia humanas lograron curarse - lo que en términos "éticos nicomaqueos" puede ser interpretado como: los que lograron adquirir eudaimonía - se mantendrán bajo cuidado de los médicos, o sea, seguirán bajo la prudencia o la virtud que les permitió sustituir la provisión

7. Tórres Gómez-Pallete, José (trad.) (1999) P. Aubenque, La prudencia en Aristóteles, Crítica, Barcelona.

Thémata. Revista de Filosofía $\mathrm{N}^{\circ} 55$ (2017) pp.: 27-40. 
divina de la que no fueron provistos y acercarse a, o transitar, la felicidad, o por lo menos acercarse a ella —o por lo menos alejarse un poco del cruel y despiadado imperio del azar. Su camino de vida continuará

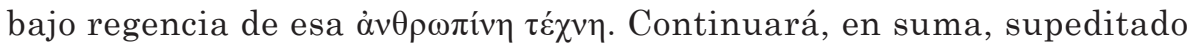
a la artificialidad de la virtud y dependiente de su ejercitación, de la misma manera que una persona desprovista de buena salud tendrá que tomar un medicamento o controlarse médicamente con alguna constancia. Mientras que aquellos que se curaron por designio divino, el deseo los conducirá a lo que les es beneficioso. ¿Qué significa esto? Deseo es aquí epithimía. O sea: la parte más pasiva del alma, conducida por impulsos instintivos y deseos — nos dice Esquines en una revelación

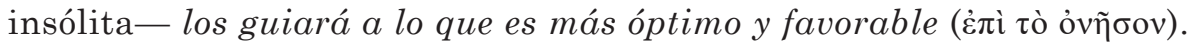
(Advertimos que todo esto sigue incursionando en el terreno de lo grave, lo escandaloso, lo incómodo y lo difícil cuando no peligroso de ser aceptado). ¿Qué tiene que ver el designio divino con el deseo? Esa es la clave que parece querer sugerirnos Esquines: mientras unos necesitan de los médicos, otros solamente necesitan darse al deseo, cultivarlo, seguirlo, pero no en un sentido glotón, hedonista o desenfrenado; se trata aquí del discurrir natural de la vida común, de la vida sin aspiraciones virtuosas ni trascendentales, de la vida que no elabora ni tiene necesidad de elaborar artificiosos medios para alcanzar la felicidad, como tener que regirse constantemente por la prudencia. Se trata de vivir, de continuar viviendo, en la "inocencia" de los deseos, tendencias, proyectos y aspiraciones de la vida natural, o de la vida bendita - que en este contexto es lo mismo que decir la vida afortunada. Solamente los desprovistos de dispensación divina - los desprovistos de gracia, bendición, fortuna - tienen que acudir a la prudencia, al sustituto. Por lo tanto, el favor del Cielo, también a veces confundido con el azar en el que oculta y auspiciosamente sopla lo divino, lo divino habita en cierto modo, en la forma de azar o de gracia; como un timonel, lo divino habita en esa epithimía, esto es, habita en los anhelos que impulsan y mueven y mantienen la vida natural, guiándola, conduciéndola por ciegas y misteriosas sendas de dicha serena y estable y bendición.

Lo que aquí hemos estado traduciendo por "lo más óptimo y favorable" corresponde a la palabra ővๆoıs, que quiere decir "lo que sirve", "lo útil", "lo que da provecho", puede además significar "lo que da placer", "lo que brinda un goce", y entre sus acepciones figura también la palabra "cuidado", en el sentido terapéutico, o sea, atención y cuidado terapéutico. Esto prueba una vez más el sentido utilitarista de la virtud para Esquines y para todos los griegos, incluso para Platón que se tuvo que tomar el trabajo de deontologizarla. Sea como fuera, significa que la naturaleza misma del desear, del querer, del más es-

Thémata. Revista de Filosofía $\mathrm{N}^{\circ} 55$ (2017) pp.: 27-40. 
pontáneo desenvolvimiento por la vida, se encargará por sí solo de proveer —al hombre divinamente agraciado y bendecido y sólo a él- de lo más óptimo y beneficioso, como si fuera un guía protector, y a la vez un servidor y un cuidador, infalible y atento siempre: sus deseos más

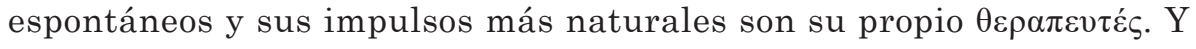
entonces, ¿qué es la prudencia? Es $\theta \varepsilon \rho \alpha \pi \varepsilon i ́ \alpha$ sustituta: es el arte que trata de sustituir, artificialmente - y precariamente, por eso mismo-, al guía y senescal que habita oculto en la voluntad y en las circunstancias del hombre dichoso, bendito y afortunado.

Me parece oportuno citar a uno de los más lúcidos intérpretes de Aristóteles, en palabras tan profundas como terribles por su verdad y su crudeza:

La consecuencia que saca de ello Aristóteles es que los hombres afortunados no deben su fortuna a su inteligencia ni, más particularmente, a su capacidad de deliberación: "Sea cual sea el lado hacia el que se inclinen, tienen éxito sin

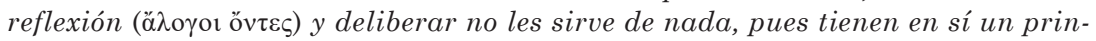
cipio que es mejor que el intelecto y la deliberación, en tanto que los otros no tienen sino el razonamiento; ellos no tienen éste, sino que están habitados por el dios». Así, si es cierto que en un sentido todo está regido por el azar, es decir, por Dios, hay que corregir esta primera afirmación precisando que la Divinidad no inspira directamente más que a los hombres que ella misma ha elegido: los otros son abandonados a las mediaciones laboriosas del razonamiento y de la deliberación.

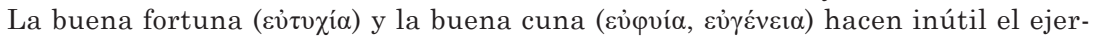
cicio del intelecto (voṽ $)$ e incluso de la virtud, que no es sino un «instrumento del intelecto». ${ }^{8}$

8. Aubenque, op. cit.

Thémata. Revista de Filosofía $\mathrm{N}^{\circ} 55$ (2017) pp.: 27-40. 


\section{Referencias bibliográficas}

Araos San Martín, J, (2003), "La ética de Aristóteles y su relación con la ciencia y la técnica", en Revista Electrónica Diálogos Educativos, año $3, \mathrm{~N}^{\circ} 6$.

Azcárate, P., (trad.) (1984), Moral a Nicómaco, Espasa-Calpe, Madrid

Chattopadhyay, G. (1997), "The utilitarian notes on the Aristotelian Ethics", en Indian Philosophical Quarterly, vol. XXIV No. 1.

Dittmar , H. (1912), Aischines von Sphettos, Studien zur Literaturgeschichte der Sokratiker, frag. 12, Weidmann , Berlin.

Fischer, J., "Das gute Leben und das Glück", [ en línea: http://www. ethik.uzh.ch/]

Mallet, J. -A., (2013) "The notion of theia moîra in Aeschines of Sphettus' fragments", en Socratica III, Academia, de Luise, F. \& Stavru, A. (eds.).

Nussbaum, M. (1995), La fragilidad del bien, Madrid, Visor.

Sinnott, E. (trad) (2007), Etica Nicomaquea, Aristóteles, Buenos Aires, Colihue.

Tórres Gómez-Pallete, José (trad.) (1999) P. Aubenque, La prudencia en Aristóteles, Crítica, Barcelona.

Yarza, I. (2001), La racionalidad de la ética de Aristóteles. Un estudio sobre la Ética a Nicómaco I, EUNSA, Navarra. 